\title{
Different bonding agents effect on adhesive bond strength: lithium disilicate glass ceramic
}

\author{
Efeito de diferentes agentes de união na cimentação adesiva em superfície \\ cerâmica de dissilicato de lítio
}

\author{
Marcos Daniel Septímio LANZA ${ }^{\text {a* }}$ (D), Walisson Arthuso VASCONCELLOS ${ }^{a}$ (D, \\ Giovani Lana Peixoto de MIRANDA ${ }^{b}$ (D), Rogéli Tibúrcio Ribeiro da Cunha PEIXOTO ${ }^{a}$ (D), \\ Lincoln Dias LANZA ${ }^{a}$ (D) \\ aUFMG - Universidade Federal de Minas Gerias, Faculdade de Odontologia, Departamento de Odontologia \\ Restauradora, Belo Horizonte, MG, Brasil \\ ${ }^{\mathrm{b}}$ Centro Universitário Newton Paiva, Belo Horizonte, MG, Brasil
}

How to cite: Lanza MDS, Vasconcellos WA, Miranda GLP, Peixoto RTRC, Lanza LD. Different bonding agents effect on adhesive bond strength: lithium disilicate glass ceramic. Rev Odontol UNESP. 2020;49:e20200020.

https://doi.org/10.1590/1807-2577.02020

\section{Resumo}

Introdução: A silanização da superfície cerâmica antes da aplicação do adesivo e/ou materiais resinosos desempenha um papel importante na resistência adesiva. Atualmente, uma nova família de sistemas adesivos foi introduzida no mercado, visando simplificar a técnica dos procedimentos adesivos durante a cimentação. Objetivo: Investigar a eficácia de diferentes soluções contendo silano e primer na superfície de cerâmicas de Dissilicato de Lítio (DLT) por meio de testes de resistência adesiva por cisalhamento. Material e método: 130 blocos cerâmicos DLT foram incluídos em resina acrílica, polidos e lavados em ultra-som por 10 minutos. Os espécimes foram divididos em 2 grupos de acordo com tratamento de superfície: Superfície Polida (PS); Ácido Hidro-Fluorídrico 9,5\% - 20s (HF). Cada grupo foi dividido em 5 sub-grupos $(\mathrm{n}=13)$ de acordo com o tipo de primer/silano: primer metálico contendo MDP (ZprimePlus, Bisco Inc); dois silanos tradicionais (MonobondPlus, IvoclarVivadent / Porcelain Prime, Bisco Inc.); mistura de silano e resina (Kerr Silane, Kerr); mistura de silano e adesivo universal (Single-bond Universal, 3M Espe). Os espécimes foram montados em um dispositivo padrão (UltradentBonding Assembly) para teste de cisalhamento Bisco Shear Bond Tester), cimentados com cimento resinoso dual (RelyX Ultimate ${ }^{\mathrm{TM}}$, $3 \mathrm{M}$ Espe.) e foto-polimerizados por 20s. 0 teste foi realizado após o período de: 24 horas e 3 meses de armazenamento em água destilada à $\pm 36^{\circ} \mathrm{C}$. Os dados foram analisados por 3-Way Anova e Teste de Tukey $(\alpha=5 \%)$. Resultado: A resistência adesiva ao cisalhamento (SBS) foi significativamente influenciada pelo tipo de tratamento da superfície, pelo tipo de agente de união utilizado e pelo armazenamento $(\mathrm{p}<0,001)$. Conclusão: Adequada resistência adesiva pode ser obtida com silanos tradicionais, combinados com o pré-tratamento de superfície com ácido HF.

Descritores: Adesão; resistência adesiva; dissilicato de lítio; cimento resinoso; silano.

\begin{abstract}
Introduction: The silanization of the ceramic surface prior to applying the adhesive and/or resinous materials plays an important role in bond strength. Nowadays, a new family of adhesive systems has been introduced into the market, aiming to simplify the technique of adhesive procedures during cementation. Objective: To investigate the effectiveness of different bonding agents containing silane and primer on Lithium Disilicate Glass Ceramic (LD) surface by shear bond strength tests. Material and method: 130 LD ceramic blocks were included in acrylic resin, polished and washed in ultrasound for 10 minutes. The specimens were divided into 2 groups according to surface treatment: Polished Surface (PS); Hydrofluoric Acid 9.5\% - 20s (HF). Each group was divided into 5 subgroups $(\mathrm{n}=13$ ) according to bonding agent type: metallic primer containing MDP (ZPrimePlus, Bisco Inc); two traditional silanes (MonobondPlus, IvoclarVivadent / Porcelain Prime, Bisco Inc.); mixture of silane and resin (Kerr Silane,
\end{abstract}


Kerr); mixture of silane and universal adhesive (Single-bond Universal, 3M Espe). The specimens were mounted in a standard device for shear testing (UltradentBonding Assembly), cemented with dual resin cement (RelyX UltimateTM, 3M Espe.) and photo-polymerized for 20s. The samples were tested after 24 hours and 3 months of storage in distilled water at $\pm 36^{\circ} \mathrm{C}$. The data were analyzed by 3 -Way Anova and Tukey's test $(\alpha=5 \%)$. Result: Shear bond strength (SBS) was significantly influenced by surface treatment, bonding agent used and storage $(\mathrm{p}<0.001)$. Conclusion: Adequate adhesive bond strength to Lithium Disilicate Glass Ceramic can be obtained with traditional silanes, combined with HF acid pretreatment surface.

Descriptors: Adhesion; adhesive strength; lithium disilicate glass ceramic; resin cement; silanes.

\section{INTRODUCTION}

The aesthetic limitations of metal-ceramic restorations have increased the search for new materials to use in clinical restorations. Currently, many ceramic systems are commercially available. Dental ceramics with a high aesthetic standard are predominantly glazed, also known as dental porcelains (glazed and translucent white ceramic), used to cover infrastructures, but having low mechanical properties. The search for a sturdier material for infrastructures involved an increase in the crystalline content, thus resulting in ceramics with better mechanical properties but with reduced aesthetic potential ${ }^{1}$.

Lithium disilicate glass ceramics (IPSe.maxCAD) are gaining popularity in restorative treatment as they satisfy the aesthetic demands of patients faster and with a favorable prognosis. These systems offer the dentist the opportunity to prepare, design and manufacture a ceramic restoration in one visit, without the need for making impressions, temporary restorations and a laboratory phase $\mathrm{e}^{2,3}$.

To obtain predictability in the cementation of ceramic restorations, excellent mechanical-chemical surface preparation is essential to promote proper adhesion between the ceramic and the dentin substrate 4 . This bonding can be achieved through the use of adhesive systems that will bond both to the tooth and to the ceramic surface, after applying hydrofluoric (HF) acid followed by a silane compound 5 . It has been speculated that HF acid conditioning of the glass ceramic surface, followed by silane, remains the "Gold Standard"6. HF acid conditioning produces partial dilution of both the glazing and crystalline phases of the ceramic, which is sufficient to obtain the surface necessary roughness ${ }^{7}$.

The silanization of the ceramic surface prior to applying the adhesive and/or resinous materials plays an important role in bond formation. Due to its bifunctional characteristic, the application of the silane favors the moistening of the ceramic surface, increasing the contact area. Furthermore, the silane binds to the silicon oxide compounds present on the ceramic surface, as well as to the organic matrix of the resin through siloxanic bonds ${ }^{8,9}$.

Recently, a new family of adhesive systems (universal adhesives) has been introduced into the market. These adhesive systems can be used in direct or indirect restorations, and are also capable of bonding to several types of substrates including composite resin, ceramics and metal alloys. Some universal adhesives contain silane and a functional monomer, such as 10-methacryloyloxydecyl dihydrogen phosphate (MDP), which helps the resin adhere to the ceramic without requiring additional primers. The versatility of the universal adhesives provides a new and simplified approach to the connection between resins and ceramics ${ }^{10}$.

As presented, the aim of the present in vitro study was to assess the effect of different ceramic pre-treatments (use, or not, of hydrofluoric acid) and the application of chemical agents (silanes or an adhesive system containing silane), as surface treatment of CAD/CAM lithium disilicate glass ceramic restorations, on shear bond strength. The effect was assessed after 24 hours and after three months of storage in distilled water, using a conventional, dual-cure resin cement. The null hypotheses tested were: (i) there will be no significant effect regarding 
surface treatments; (ii) there will be no significant effect regarding type of bonding agent; (iii) there will be no significant effect regarding storage.

\section{METHODOLOGY}

One hundred thirty ceramic blocks of Lithium Disilicate (IPSe.maxCAD, Ivoclar-Vivadent) were cut measuring $7 \times 7 \times 3 \mathrm{~mm}$ and submitted to the crystallization process in a special oven for this purpose (Programat $(\AA)$ ), at a temperature of $840-850{ }^{\circ} \mathrm{C}$ for 25 minutes. After crystallization, each block was set in a PVC matrix with the aid of a chemically activated acrylic resin. The surface of each specimen was prepared with 180 and 400 grit sandpaper for 20 seconds of each sanding, under constant refrigeration. Between each polishing sequence, the specimens were washed in ultrasound-deionized water.

Two groups were created $(n=65)$ based on the surface pre-treatment: (1) PS: polished surface; (2) HF: 9.5\% Hydrofluoric Acid (Bisco Inc, Schaumburg, IL, EUA), applied for 20s, rinsed for 10s, and air-dried for 10s. Each group was subdivided into five groups $(n=13)$ according to the type of bonding agent being investigated: ZPP - Metal Primer (ZPrime Plus, Bisco Inc, Schaumburg, IL, USA); MBP - Traditional Silane (IvoclarVivadent); PP - Traditional Silane (Porcelain Primer/Bisco Inc, Schaumburg, IL, EUA); KS - Mixture of silane with resin (Kerr Silane / Kerr Corp, Orange, CA, EUA); SBU - Mixture of silane with universal adhesive (Single Bond Universal, 3M ESPE, St Paul, MN, EUA) (Figure 1). The silanization protocol followed the manufacturer's instructions. In summary, for the commercial primers/silanes ZPP, MBP, PP and KS, two drops of silane were applied directly to the surface, waited 30s and dried with jets of oil-free air. A layer of the SBU adhesive was applied directly to the surface, waited 20 s and dried with jets of oil-free air, with subsequent photo-activation for 20 s with an LED light polymerization unit (Bluephase Style, IvoclarVivadent; Schaan, Liechtenstein) with $1.100 \mathrm{~mW} / \mathrm{cm}^{2}$.

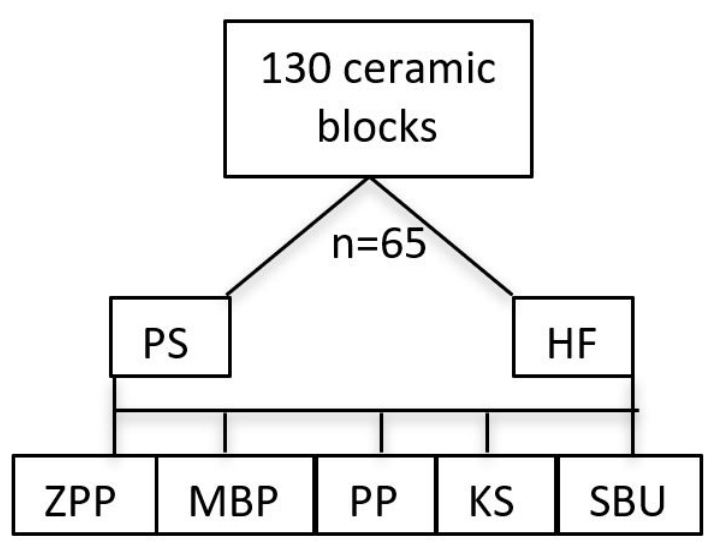

Figure 1. Flowchart of the study.

The specimens were randomly distributed among the experimental groups according to a computer program ${ }^{11}$. Each specimen was assembled and set in a standard assembler (Ultradent Bonding Assembly, Ultradent Products Inc., South Jordan, UT, USA) with a plastic platform with internal diameter of $2.38 \mathrm{~mm}$, to obtain a final sectional area of $4.45 \mathrm{~mm}^{2}$. The mold was filled with conventional, dual-cure resin cement (RelyX Ultimate 3M ESPE, St Paul, MN, EUA) using a self-mixing and photo-activated syringe with an LED light polymerization unit (Bluephase Style, IvoclarVivadent; Schaan, Liechtenstein) with $1.100 \mathrm{~mW} / \mathrm{cm}^{2}$, initially for 1 second, followed by manual compression of the resin cement inside the mold against the ceramic surface, with an additional 20s of photo-activation. This protocol was adopted to eliminate air bubbles at the 
cementation interface and internally in the cement. The power of the polymerization unit was measured before each use with the aid of a radiometer (Model 100, KERR Corporation, Orange, CA USA). After cementing, the matrix was disassembled and a cylinder of approximately $3 \mathrm{~mm}$ height was created. Two cylinders of resin cement were added to each ceramic surface. The specimens were stored in distilled water ( $\mathrm{pH} \mathrm{6.3)}$ at $\pm 37{ }^{\circ} \mathrm{C}$. After 24 hours, one cylinder was tested using the shear method and the other remained adhered in order to conduct the test after three months of storage. The water was renewed every month until the specimen was tested. This methodology is intended to avoid contamination of the water by residual monomers.

The test of bond strength was conducted using a shear test machine (Bisco Shear Bond tester, Schaumburg, IL, USA). The loading speed at the resin cement/ceramic surface interface was $0.5 \mathrm{~mm} / \mathrm{min}$ until failure. The failure mode was classified using a 40x magnification digital microscope (Nikon Eclipse 80i microscope; Nikon Instruments, Amsterdam, Netherlands).

Failures occurring at the adhesive interface and having less than $33 \%$ cement remaining on the ceramic surface were classified as "adhesive failure". Failures having between 33\% and 66\% cement remaining on the ceramic surface were classified as "mixed failure". Those with more than $66 \%$ cement remaining on the ceramic surface were classified as "cohesive failure" 12 .

Data were analyzed using 3-way ANOVA (Sigma Plot 12.0, Jandel Scientific, USA) and for multiple comparison by pairs (Tukey test) to investigate the effects of the surface treatments, of the bonding agents and of storage time in water. The tests were conducted with $\alpha=5 \%$ $(\mathrm{p}<0.05)$.

\section{RESULT}

Results in $M p a$ are shown in Table 1 and Figure 2. The shear bond strength (SBS) was influenced significantly by the type of surface treatment, the type of bonding agent used and the storage $(p<0.001)$.

Table 1. Mean values of Shear Strength expressed in MPa \pm DP

\begin{tabular}{|c|c|c|c|c|}
\hline Silanes & \multicolumn{2}{|c|}{24 HOURS } & \multicolumn{2}{|c|}{3 MONTHS } \\
\hline ZPP & $15.10 \pm 2.7 \mathrm{~A}, \mathrm{~b}$ & $3.13 \pm 0.7$ B,a & $7.72 \pm 1.9 \mathrm{X,c}$ & $0.0 \pm 0.0 \mathrm{Y}, \mathrm{a}$ \\
\hline MBP & $17.01 \pm 5.2 \mathrm{~A}, \mathrm{ab}$ & $6.01 \pm 2.0$ в,a & $11.9 \pm 4.6^{\mathrm{X}, \mathrm{b}}$ & $1.8 \pm 1.9 \mathrm{Y}, \mathrm{a}$ \\
\hline PP & $19.09 \pm 7.6 \mathrm{~A}, \mathrm{a}$ & $4.30 \pm 3.0 \mathrm{~B}, \mathrm{a}$ & $18.82 \pm 5.0 \mathrm{~A}, \mathrm{a}$ & $0.70 \pm 1.0 \mathrm{Y}$ \\
\hline KS & $15.36 \pm 6.7 \mathrm{~A}, \mathrm{~b}$ & $2.49 \pm 1.4$ B,a & $7.19 \pm 3.9 \times, c$ & $0.00 \pm 0.0 \mathrm{Y}, \mathrm{a}$ \\
\hline
\end{tabular}

Means followed by different Uppercase letters (line) and Lowercase (column) differ statistically according to the Tukey test ( $\mathrm{p}$ 0.05). PS (Polished Surface). HF (Hydrofluoric Acid). ZPP (ZPrimePlus). MBP (MonoBond Plus). PP (Porcelain Primer). KS (Kerr Silane). SBU (SingleBond Universal).

The HF group showed higher bond strength values, independent of the bonding agent used and the storage time, compared to the PS group.

After HF conditioning, the traditional silane (PP) showed higher bond strength results, and the adhesive system (SBU) showed lower results, after 24 hours of storage. However, it is worth emphasizing that these bonding agents showed no significant difference between the storage intervals.

After 24 hours, analysis of the fracture mode (Figures 3 and 4) revealed a predominance of mixed failure for most of the silane groups when HF treatment was used. For the PS groups, analysis of the fracture mode revealed more adhesive failure regardless of the bonding agent 
and storage time, with spontaneous decementation after three months for the ZPP and KS silane groups.

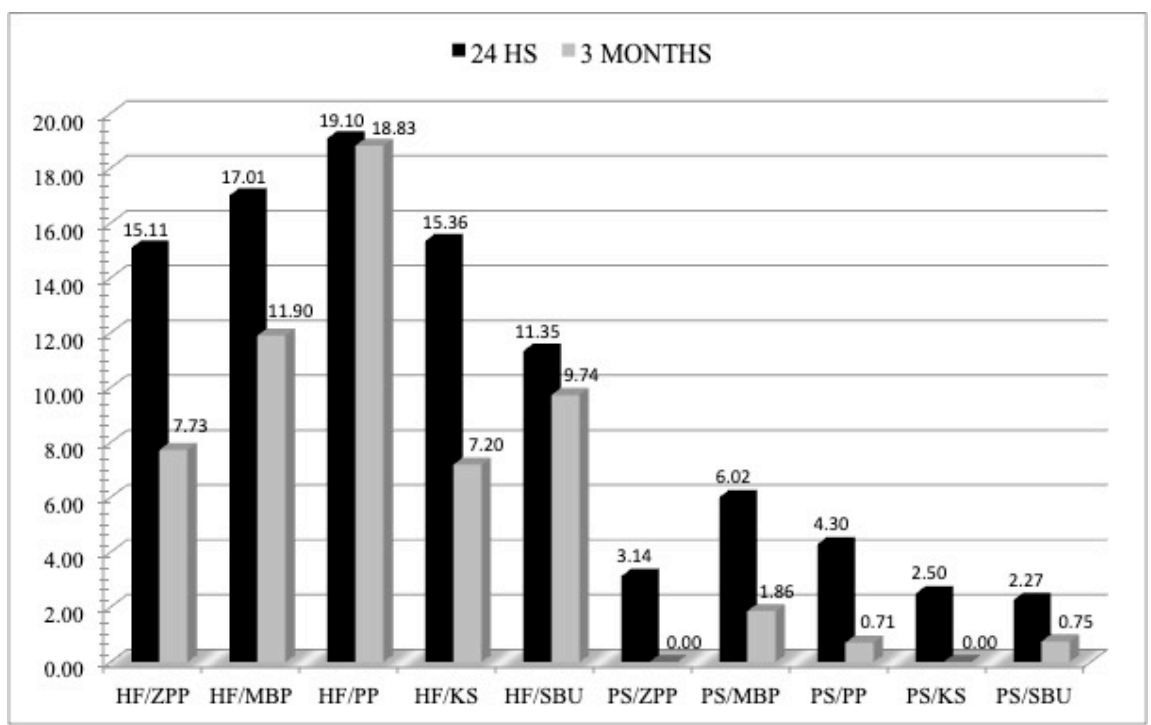

Figure 2. Mean values expressed in MPa 24 hours and 3 months.
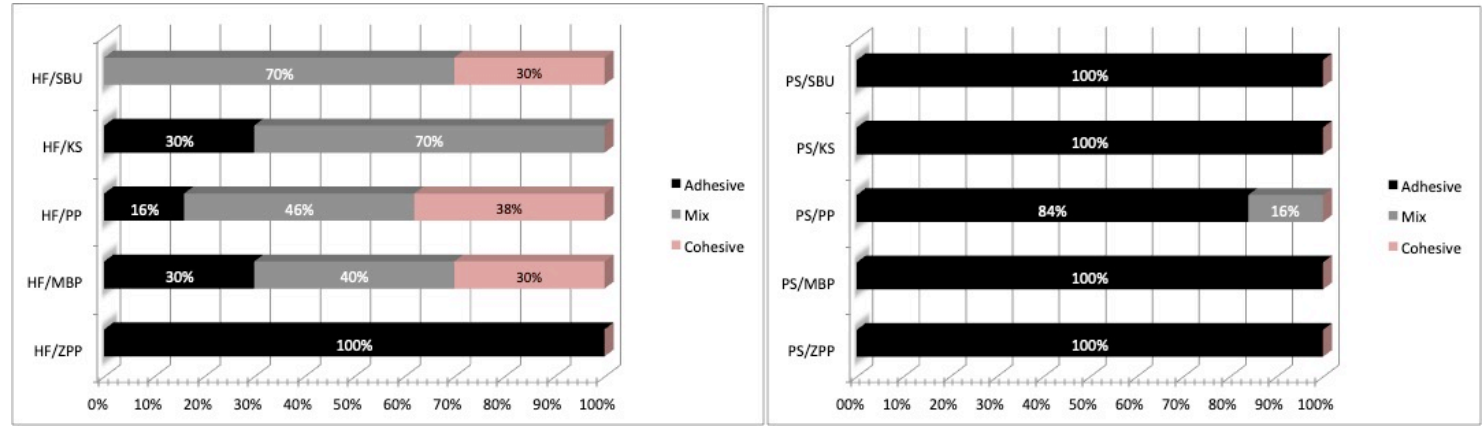

Figure 3. Facture Mode Analysis after 24 hours.

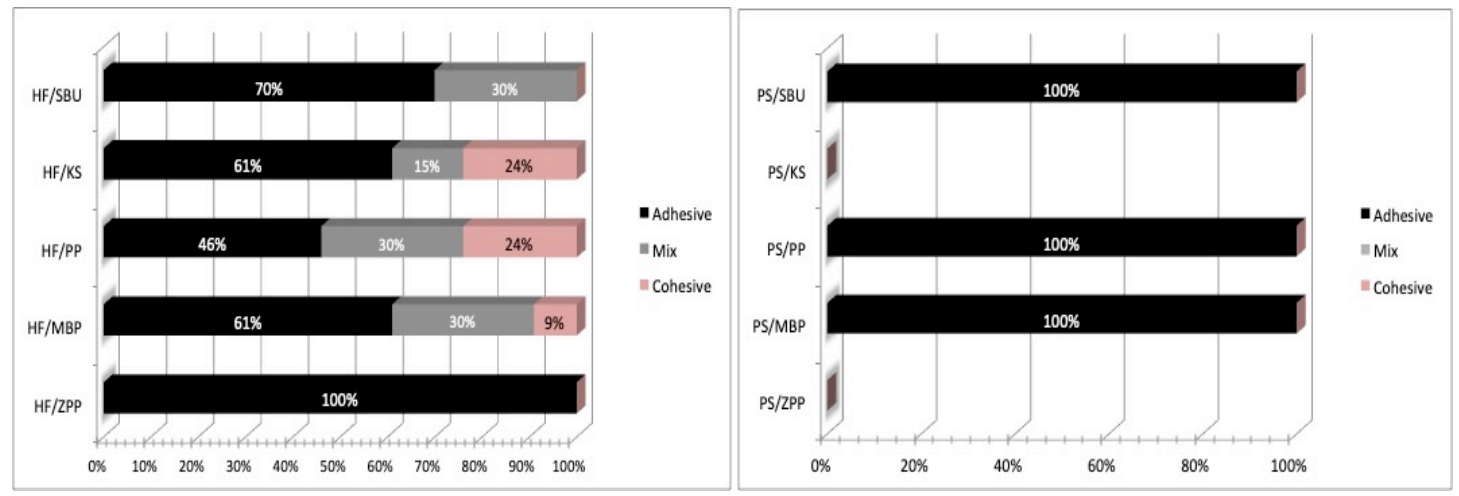

Figure 4. Fracture Mode Analysis after 3 months. 


\section{DISCUSSION}

In the present study, all the investigated factors (surface treatment, bonding agent and storage) had a significant impact on the shear strength between the resin cement and the lithium disilicate glass ceramic. Thus, the null hypotheses tested must be rejected.

According to the results obtained in the present study, it can be observed that bond strength was impaired in the groups in which the lithium disilicate surface was not conditioned (PS), and the application of the bonding agents did not result in gains in bond strength. This suggests that only the chemical treatment of the surface with silane/primer/adhesive does not favor improvement in the bond strengths to the lithium disilicate glass ceramic. On the other hand, when the surface was conditioned with HF, a significant increase in bond strength was found, regardless of the bonding agent used. These data are corroborated by some authors who reported that HF selectively conditions and dissolves the glazed matrix of the ceramic and causes changes in the surface, providing a topographic pattern that favors a strong, micromechanical bond with resinous materials, reflecting high bond strength values ${ }^{8,13}$.

Silanization of the ceramic surface, prior to the application of the adhesive and/or resinous materials, has been a standard procedure in glass ceramic restorations as its importance in bond formation is well established. The silanes form a large group of organic compounds that contain, essentially, one or more silicon (Si) atoms. In general, they present the chemical formula R-Si-(OR') $)_{3}$ and are considered monofunctional, bifunctional and/or trifunctional agents, depending on the quantity of $\mathrm{Si}$ atoms. These compounds are capable of promoting chemical bonding with organic surfaces, such as composite resins and polymers, as well as binding to the inorganic compounds present on the ceramic surface by means of the siloxane covalent bonds in both cases ${ }^{14,15}$.

The current market trend is to launch adhesives considered "universal" or "multi-mode". Some of these adhesives have components that allow them to bond to the glass or zirconium ceramic, noble and non-noble alloys, and composites ${ }^{16}$. According to the manufacturers, they still have the advantage of being compatible with all the resin cements. Therefore, they are adhesives that seek to reduce the sensitivity of the technique with simplification of its use. However, the universal adhesives have only been on the market for a short time and little information is available about their performance on ceramic surfaces. Some authors report that, although the bond strength between resinous materials with the ceramic surface based on leucite conditioned with fluoride acid was improved when universal adhesives were used, conventional surface treatment using a silane is preferable to a simplified procedure that uses only universal adhesive ${ }^{10,17}$. In addition, other authors have reported that the capacity of universal adhesives to obtain an appropriate and lasting bond to ceramics based on lithium disilicate seems limited, and an effective bond is found with the use of specific, traditional silane as a separate step after conditioning with HF acid 18 . The results of the present study corroborate these findings since the best bond strength results occurred when traditional silane was used.

Due to the lack of stable chemical bonding of the universal adhesives, it has been mentioned that the silane contained in the adhesive systems does not produce a significant chemical bond with the ceramic surface ${ }^{10,13,19}$. The bond strength was significantly improved when the silane was applied before applying the universal adhesive. Thus, the incorporation of silane in the adhesive itself seems ineffective in improving the ceramic-resin bond.

This can be explained by the presence of a mixture of several components in the same flask, and by the inhibition of the bis-GMA that interrupts the action of the silane in the condensation reaction of the hydroxyl group on the ceramic surface ${ }^{20}$. Furthermore, the functional acid monomer (10-MDP), present in some universal adhesives, can prevent the ideal chemical 
interaction between silane and the ceramic surface, due to the tendency to undergo premature hydrolysis in an acidic environment ${ }^{10}$.

The failure mode observed was, mainly, mixed and/or cohesive for all silanes tested when HF acid was applied. This indicates a good bond and contact with the ceramic surface. Conversely, for the polished surface (PS) group, the failure mode was mainly interfacial (adhesive) for both storage times. This suggests that that interface was the weakest link in the connection. This may suggest that the reduction of the total silane concentration in the adhesives compromised the performance of those materials over the long term. These data are corroborated by other, recent studies ${ }^{21}$.

It is interesting to emphasize that the degradation of the molecular bond between surfaces is strongly influenced by the hydrophilic and/or hydrophobic capacity of the resinous materials and adhesive systems, since differences in composition permit greater or lesser water absorption. Water sorption favors the weakening of siloxane bond caused by hydrolysis and swelling of the material, causing stress at the adhesive interface that will play an important role in weakening the bond. Moreover, this effect may be due to the hydrolytic cleavage of siloxane connections in the interfacial layer, which reduces the bond strength ${ }^{22,23}$. Several studies have reported that high bond strengths obtained after $24 \mathrm{~h}$ are compromised after aging in water with a significant reduction in the bond strength between the resin and the ceramic ${ }^{24}$. These findings are corroborated in the present study because the results revealed a notable reduction in bond strength, regardless of the surface treatment and bonding agents used on the ceramic surface, although some authors recommend greater storage time in a medium of artificial saliva $^{25}$.

The shear test was chosen for its advantages, having small areas and for the ease of preparing the sample ${ }^{26}$, since it does not require cutting procedures such as those used for sample preparation in the micro-tensile bond strength test. However, it is known that the bond strength test, using the shear test, is being scrutinized increasingly due to it limitations in demonstrating true failure. Nevertheless, it is also known as a relatively simple and replicable laboratory method, particularly when accompanied by failure mode assessment. Thus, the shear strength test proved to be satisfactory and effective in the present study, in which the data supplied and the significant differences found can be drawn from the conclusions.

\section{CONCLUSION}

Bond strengths higher than lithium disilicate glass ceramic can be obtained after conditioning with HF acid.

The type of bonding agent influences the adhesive strength to the ceramic surface of lithium disilicate.

The shear strength decreased after storage in water over the medium term, regardless of the type of surface treatment and bonding agent used.

Universal adhesive has not shown promising results in adhesive strength, although manufacturers have indicated its use as a substitute for traditional silanes.

\section{REFERENCES}

1. Kelly JR, Benetti P. Ceramic materials in dentistry: historical evolution and current practice. Aust Dent J. 2011 Jun;56(Suppl 1):84-96. http://dx.doi.org/10.1111/j.1834-7819.2010.01299.x. PMid:21564119.

2. Guess PC, Zavanelli RA, Silva NRFA, Bonfante EA, Coelho PG, Thompson VP. Monolithic CAD/CAM lithium disilicate versus veneered Y-TZP crowns: comparison of failure modes and reliability after fatigue. Int J Prosthodont. 2010 Sep-Oct;23(5):434-42. PMid:20859559. 
3. Raigrodski AJ, Hillstead MB, Meng GK, Chung K-H. Survival and complications of zirconia- based fixed dental prostheses: a systematic review. J Prosthet Dent. 2012 Mar;107(3):170-7. http://dx.doi.org/10.1016/S0022-3913(12)60051-1. PMid:22385693.

4. Alex G. Preparing porcelain surfaces for optimal bonding. Compend Contin Educ Dent. 2008 JulAug;29(6):324-35, quiz 336. PMid:18795637.

5. Shimakura Y, Hotta Y, Fujishima A, Kunii J, Miyazaki T, Kawawa T. Bonding strength of resin cement to silicate glass ceramics for dental CAD/CAM systems is enhanced by combination treatment of the bonding surface. Dent Mater J. 2007 Sep;26(5):713-21. http://dx.doi.org/10.4012/dmj.26.713. PMid:18203473.

6. Klosa K, Boesch I, Kern M. Long-term bond of glass ceramic and resin cement: evaluation of titanium tetrafluoride as an alternative etching agent for lithium disilicate ceramics. J Adhes Dent. 2013 Aug;15(4):377-83. http://dx.doi.org/10.3290/j.jad.a29381. PMid:23534032.

7. Meng X, Yoshida K, Atsuta M. Influence of ceramic thickness on mechanical properties and polymer structure of dual-cured resin luting agents. Dent Mater. 2008 May;24(5):594-9. http://dx.doi.org/10.1016/j.dental.2007.06.014. PMid:17669482.

8. Brentel AS, Ozcan M, Valandro LF, Alarça LG, Amaral R, Bottino MA. Microtensile bond strength of a resin cement to feldpathic ceramic after different etching and silanization regimens in dry and aged conditions. Dent Mater. 2007 Nov;23(11):1323-31. http://dx.doi.org/10.1016/j.dental.2006.11.011. PMid:17188745.

9. Kitayama S, Nikaido T, Takahashi R, Zhu L, Ikeda M, Foxton RM, et al. Effect of primer treatment on bonding of resin cements to zirconia ceramic. Dent Mater. 2010 May;26(5):426-32. http://dx.doi.org/10.1016/j.dental.2009.11.159. PMid:20102781.

10. Kim RJ-Y, Woo J-S, Lee I-B, Yi Y-A, Hwang J-Y, Seo D-G. Performance of universal adhesives on bonding to leucite-reinforced ceramic. Biomater Res. 2015 May;19(1):11. http://dx.doi.org/10.1186/s40824015-0035-1.

11. Research Randomizer [Internet]. 2020 [cited 2007 Mar 27]. Available from: http://www.randomizer.org

12. Matinlinna JP, Lassila LV. Enhanced resin-composite bonding to zirconia framework after pretreatment with selected silane monomers. Dent Mater. 2011 Mar;27(3):273-80. http://dx.doi.org/10.1016/j.dental.2010.11.002. PMid:21122907.

13. Kalavacharla VK, Lawson NC, Ramp LC, Burgess JO. Influence of etching protocol and silane treatment with a universal adhesive on lithium disilicate bond strength. Oper Dent. 2015 Jul-Aug;40(4):372-8. http://dx.doi.org/10.2341/14-116-L. PMid:25535784.

14. Matinlinna JP, Lassila LVJ, Ozcan M, Yli-Urpo A, Vallittu PK. An introduction to silanes and their clinical applications in dentistry. Int J Prosthodont. 2004 Mar-Apr;17(2):155-64. PMid:15119865.

15. Hooshmand T, Matinlinna JP, Keshvad A, Eskandarion S, Zamani F. Bond strength of a dental leucitebased glass ceramic to a resin cement using different silane coupling agents. J Mech Behav Biomed Mater. 2013 Jan;17:327-32. http://dx.doi.org/10.1016/j.jmbbm.2012.08.020. PMid:23122713.

16. Loguercio AD, Paula EA, Hass V, Luque-Martinez I, Reis A, Perdigão J. A new universal simplified adhesive: 36-month randomized double-blind clinical trial. J Dent. 2015 Sep;43(9):1083-92. http://dx.doi.org/10.1016/j.jdent.2015.07.005. PMid:26159382.

17. Lee Y, Kim J-H, Woo J-S, Yi Y-A, Hwang J-Y, Seo D-G. Analysis of self-adhesive resin cement microshear bond strength on leucite-reinforced glass-ceramic with/without pure silane primer or universal adhesive surface treatment. BioMed Res Int. 2015;2015:361893.

http://dx.doi.org/10.1155/2015/361893. PMid:26557660. 
18. Cuevas-Suárez CE, de Oliveira da Rosa WL, Vitti RP, da Silva AF, Piva E. Bonding strength of universal adhesives to indirect substrates: a meta-analysis of in vitro studies. J Prosthodont. 2020 Apr;29(4):298-308. http://dx.doi.org/10.1111/jopr.13147. PMid:31994803.

19. Yoshihara K, Nagaoka N, Sonoda A, Maruo Y, Makita Y, Okihara T, et al. Effectiveness and stability of silane coupling agent incorporated in 'universal' adhesives. Dent Mater. 2016 Oct;32(10):1218-25. http://dx.doi.org/10.1016/j.dental.2016.07.002. PMid:27461880.

20. Chen L, Shen H, Suh BI. Effect of incorporating BisGMA resin on the bonding properties of silane and zirconia primers. J Prosthet Dent. 2013 Nov;110(5):402-7. http://dx.doi.org/10.1016/j.prosdent.2013.04.005. PMid:24007793.

21. Makishi P, André CB, Silva JPL, Bacelar-Sá R, Correr-Sobrinho L, Giannini M. Effect of storage time on bond strength performance of multimode adhesives to indirect resin composite and lithium disilicate glass ceramic. Oper Dent. 2016 Sep-Oct;41(5):541-51. http://dx.doi.org/10.2341/15-187-L. PMid:27379836.

22. Amaral R, Ozcan M, Bottino MA, Valandro LF. Resin bonding to a feldspar ceramic after different ceramic surface conditioning methods: evaluation of contact angle, surface $\mathrm{pH}$, and microtensile bond strength durability. J Adhes Dent. 2011 Dec;13(6):551-60. http://dx.doi.org/10.3290/j.jad.a19815. PMid:21246072.

23. Matinlinna JP, Lassila LV. Experimental novel silane system in adhesion promotion between dental resin and pretreated titanium. Part II: effect of long term water storage. Silicon. 2010 Apr;2(2):79-85. http://dx.doi.org/10.1007/s12633-010-9039-6.

24. Roulet JF, Soderholm KJ, Longmate J. Effects of treatment and storage conditions on ceramic/composite bond strength. J Dent Res. 1995 Jan;74(1):381-7. http://dx.doi.org/10.1177/00220345950740011501. PMid:7876433.

25. Tian T, Tsoi JK-H, Matinlinna JP, Burrow MF. Aspects of bonding between resin luting cements and glass ceramic materials. Dent Mater. 2014 Jul;30(7):e147-62. http://dx.doi.org/10.1016/j.dental.2014.01.017. PMid:24612840.

26. Shimada Y, Yamaguchi S, Tagami J. Micro-shear bond strength of dual-cured resin cement to glass ceramics. Dent Mater. 2002 Jul;18(5):380-8. http://dx.doi.org/10.1016/S0109-5641(01)00054-9. PMid:12175577.

\section{CONFLICTS OF INTERESTS}

The authors declare no conflicts of interest.

\section{${ }^{*}$ CORRESPONDING AUTHOR}

Marcos Daniel Septímio Lanza, UFMG - Universidade Federal de Minas Gerais, Faculdade de Odontologia, Av. Presidente Antonio Carlos, 6627, Pampulha, 31270-901 Belo Horizonte - MG, Brasil, e-mail: lanza.mds@gmail.com

Received: March 27, 2020

Accepted: July 6, 2020 